\title{
O Primeiro Doutor em CiênCIAS Matemáticas no B RaS IL: Manuel da CunHa Galvão
}

\author{
Mônica de Cássia Siqueira Martines \\ Universidade Federal do Triângulo Mineiro - UFTM - Brasil \\ Sergio Roberto Nobre \\ Universidade Estadual Paulista - UNESP-Brasil \\ (aceito para publicação em novembro de 2017)
}

\begin{abstract}
Resumo
Neste artigo, pretendemos relatar parte da pesquisa de Doutorado defendido no ano de 2014, referente ao primeiro Bacharel em Matemáticas a obter o título de Doutor em Ciências Matemáticas. Nossa busca foi impulsionada por tentar compreender a Matemática que foi desenvolvida nas Teses de Doutorado apresentadas à Escola Militar entre $1842 \mathrm{e}$ 1858 no Brasil. No entanto, para compreendermos o por quê deste grau no Brasil, iniciamos uma pesquisa sobre a Academia Real Militar. Queríamos saber como ela fora criada, quais mudanças teriam ocorrido ao longo dos anos e como surgiu a ideia de conceder o grau de doutor em Ciências Matemáticas. Através das leituras dos decretos e leis sobre a Academia Real Militar e suas reformas, percebemos uma série de decretos que atualizaram e deram novas diretrizes a Academia Real Militar a transformando em 1839 em Escola Militar e, em 1842 nessa escola, instituiu-se o grau de Doutor em Ciências Matemáticas. Neste ano e nos seguintes, até 1846 , os professores da referida escola receberam o título sem outra exigência qualquer. Com a publicação da Regularização de 29 de setembro de 1846, são dadas orientações àqueles que desejassem obter o título de Doutor. Nesse contexto que apresentamos Manuel da Cunha Galvão, que em 22 de dezembro de 1847, entregava sua dissertação de doutorado ao Dr. José Gomes Jardim e, no dia 28 de maio de 1848, recebe seu grau de Doutor na presença do Imperador D. Pedro II.
\end{abstract}

RBHM, Vol. 17, n³3, p. 31-48, 2017 
Palavras-chave: História da Matemática, Primeiro Doutor em Ciências Matemáticas, Grau de Doutor em Ciências Matemáticas, Manuel da Cunha Galvão.

[FIRST DOCTOR IN MATHEMATICS SCIENCE IN BRAZIL: MANUEL DA CUNHA GALVÃo]

\begin{abstract}
In this article, we report of the $\mathrm{PhD}$ research defended in 2014, referring to the first Bachelor of Mathematics to obtain the title of Doctor of Mathematical Sciences. Our search was driven by trying to understand the mathematics that was developed in the Doctoral Thesis submitted to the Military School between 1842 and 1858 in Brazil. However, to understand why this degree in Brazil, began a survey of the Royal Military Academy. We wanted to know how it was created, what changes have occurred over the years and how did the idea to award the degree of Doctor of Mathematical Sciences. Through the reading of decrees and laws of the Royal Military Academy and his reforms, we see a series of decrees that have updated and given new guidelines the Royal Military Academy at turning in 1839 in the Military School and in 1842 this school, established the degree Doctor of Mathematical Sciences. This year and the next, until 1846, the said school teachers received the title without any other requirement. With the publication of Regularization of September 29, 1846, they are given guidance to those wishing to obtain the title of Doctor. In this context we present Manuel da Cunha Galvão, who on December 22, 1847, delivered his doctoral dissertation Dr. José Gomes Jardim and, on 28 May 1848, received his PhD degree in the presence of Emperor D. Pedro II.
\end{abstract}

Keywords: History of Mathematics, First Doctor of Mathematical Sciences, Degree of Doctor of Mathematical Sciences, Manuel da Cunha Galvão.

\title{
1. Introdução: a implantação do grau de Doutor em Ciências Matemáticas: um longo caminho
}

Em 1810, quando a Academia Real Militar foi criada no Brasil, foram estipulados alguns critérios para que os alunos fossem admitidos à estudarem nela. A quantidade de regras disponibilizadas no documento de criação da Academia é extensa, mas a exigência para o ingresso em tal academia nem tanto. Apenas era exigido ao candidato:

\footnotetext{
a. ter ao menos 15 anos e;

b. dar conta das quatro primeiras operações Matemáticas.
} 
Aos que soubessem a língua latina, ou a língua grega, ou ainda, as línguas "vivas”, ficariam reservados os primeiros lugares, não somente na seleção e matrícula, mas também para assistir as aulas e quando fossem despachados (BRASIL, 1810).

Essas regras perduraram durante todo a regência de D.João VI e mesmo quando em 1822, o Brasil ficou independente de Portugal e a Academia passou a ser chamada Academia Imperial Militar, mas seus estatutos não foram alterados, nem a exigência para ingresso e muito menos as disciplinas que eram lecionadas.

Somente em 1831 foi obtida autorização para reformas nos estatutos: O Artigo 15, $\S 2^{\circ}$ da Lei de 15 de Novembro de 1831, disposto no Capítulo V da referida Lei, traz por título "Da Fixação das Despezas do Ministerio dos Negocios da Guerra." São os valores que deverão ser despendidos durante todo o

"anno financeiro do $1^{\circ}$ de Julho de 1832 ao ultimo de junho de 1833. [...] $\$ 2^{\circ}$ Com a Academia Militar, [...] Ficando o Governo autorizado a fazer na Academia a reforma no systema dos estudos para as differentes armas do Exercito, de que dará conta à Assembléa Geral Legislativa”. (BRASIL, 1831).

A partir daí, a Academia Imperial Militar passou por várias mudanças em seu estatuto. Entre elas, destacamos as reformas feitas através do:

i. $\quad$ Decreto de 9 de Março de 1832. Onde a principal mudança se concentra na reunião das Academias Militar e da Marinha; além de criar o curso Matemático;

ii. Decreto de 22 de Outubro de 1833. Neste decreto observa-se a separação das Academias, altera o rol de disciplinas a ser ministradas e, extingue o curso Matemático;

iii. Decreto de 23 de Fevereiro de 1835, este decreto cancela o decreto de 1833 em relação às disciplinas que haviam sido alteradas;

iv. $\quad \mathrm{n}^{\circ} 25$ de 14 de Janeiro de 1839 , aqui a principal alteração é a alternância de Academia Militar para Escola Militar;

v. Decreto de 09 de Março de 1842. Este decreto é importante, pois ele reorganiza as disciplinas e institucionaliza o grau de doutor em Ciências Matemáticas na Escola Militar;

vi. Decreto de 01 de março de 1845, regulamenta o grau de bacharel em Matemáticas;

vii. Regularização de 29 de setembro de 1846, regulamenta o grau de doutor em Ciências Matemáticas.

RBHM, Vol. 17, n³3, p. 31-48, 2017 
Assim, verificamos que o grau de Doutor em Ciências Matemáticas foi criado na Escola Militar pelo artigo 19 do Decreto $\mathrm{n}^{\circ} 140$ de 09 de março de 1842 do Império do Brasil.

"Os Alunnos que se mostrarem approvados plenamente em todos os sete annos do Curso completo da Escola Militar, e se habilitarem pela fôrma que for determinada nas Instrucções, ou Regulamento do Governo, receberão o Gráo de Doutor em Sciencias Mathematicas, e só os que o obtiverem poderão ser oppositores aos lugares de Substitutos.

Os Lentes e Substitutos actuaes receberão o referido Gráo sem outra alguma habilitação que o título de suas nomeações". (BRASIL, 1842.)

De acordo com o Decreto de 1842, os professores desta escola receberam o referido grau sem nenhuma outra exigência. Foram eles: Jubilados (Aposentados): José Saturnino Costa Pereira, José Victorino dos Santos e Sousa, Frei Pedro de Santa Mariana, João Paulo dos Santos Barreto, Frei José da Costa Azevedo, Francisco Cordeiro da Silva Torres e Alvim. Efetivos: José Pedro Nolasco Pereira da Cunha, Antônio Joaquim de Sousa, Manuel Felizardo de Sousa e Melo, Antônio Eugênio Fernando Soulier de Souve, Pedro d'Alcântara Bellegarde, Joaquim José de Oliveira, Antônio José de Araújo, Antônio Manuel de Melo. Substitutos: José Maria da Silva Paranhos, José Joaquim da Cunha, Antonio Francisco Coelho (MILLER, 2003, p.89, 90).

A aprovação do regulamento para a execução do Artigo 19, o qual trata da obtenção do grau de Doutor em Ciências Matemáticas, foi publicada em 29 de Se tembro de 1846. Neste regulamento ficou estabelecido que o aluno que fosse aprovado nas matérias do sétimo ano da Escola Militar, obteria o grau de Bacharel em Matemáticas. O Bacharel em Matemáticas que pretendesse o grau de Doutor, deveria fazer uma requisição ao Diretor da escola. Para tanto o aluno deveria entregar uma certidão que comprovass e ter passado em todos os exames preparatórios exigidos nos estatutos, e também ter obtido aprovações plenas em todas as matérias ensinadas na escola.

Os exames preparatórios a essa época se referiam aos pré-requisitos para ingressar na Escola Militar, os quais esram:

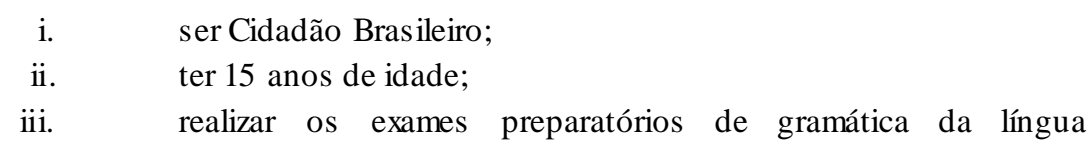
Nacional, de tradução e leitura da língua francesa, e dominar as quatro operações de Aritmética, dominar a Geografia, e o domínio da gramática Latina também era exigência aos candidatos ao curso de Engenharia; 
iv. obter licença do Governo.

Já as aprovações plenas a que se refere o regulamento de 1846, diz respeito a forma de avaliação pela qual os alunos passavam nessa época. A mesma está descrita no Decreto de 22 de Outubro de 1833 e, que nos informa que o ano letivo tinha início no primeiro dia útil do mês de março, e se encerrava no último dia útil do mês de outubro. Os exames aconteciam no mês de novembro. Para os exames, os professores preparavam uma lista de pontos a serem sorteados. Vinte e quatro horas antes da realização do mesmo marcava-se um encontro entre os professores e os alunos do exame e sorteava-se o ponto. No dia seguinte, os alunos tinham uma hora para apresentar o ponto sorteado e, cada um dos três professores avaliadores, tinha trinta minutos para arguir. Ao final se o aluno recebesse três AA esse seria aprovado plenamente; se recebesse dois $\mathbf{A A}$ e um $\mathbf{R}$, teria sido aprovado pela maior parte; e se recebesse dois ou três $\mathbf{R} \mathbf{R}$, seria reprovado.

Munido desse requerimento e das certidões exigidas o Bacharel que quisesse obter o grau de doutor em Ciências Matemáticas deveria, ainda, entregar ao Diretor da Escola, quarenta exemplares de uma dissertação feita pelo bacharel sobre qualquer ponto da Ciência Matemática dos mais profundos, e dos que se ensinavam nos três últimos anos.

A dissertação de Doutorado, deveria ser vista e aprovada por um Lente catedrático de escolha do doutorando. O mesmo deveria verificar se na dissertação não haveria nada que deslustrasse a Escola, ou que ofendesse as Leis ou a qualquer indivíduo, não julgando sobre o merecimento científico.

Feito isso, a Congregação dos professores, designaria quatro membros examinadores e o dia do ato. O presidente do exame seria o professor escolhido pelo candidato e que tivesse aprovado a Dissertação. Cada examinador poderia arguir o candidato por meia hora.

Embora o regulamento tenha sido aprovado em 1846, foi somente no final do ano de 1847 que as primeiras Dissertações de Doutorado começaram a ser entregues e, assim temos os primeiros Doutores em Matemática que receberam o referido grau após entregar a Dissertação nas condições determinadas pelo regulamento.

\section{Os primeiros doutores em Ciências Matemáticas com entrega de dissertação}

Verificamos o conferimento do grau aos seis primeiros doutores em Matemática no Brasil após a entrega de uma dissertação de Doutorado através do "Termo de Grau de Doutor $n^{\circ} 1$, 1846-1858" disponível no Acervo do Museu da Escola Politécnica da Universidade Federal do Rio de Janeiro, documento este que tivemos acesso e que às páginas 13, 14 e 15 nos informa que o primeiro Doutor em Matemáticas foi Manuel da Cunha Galvão, seguido por Ignacio da Cunha Galvão, João Baptista de Castro Moraes 
Antas, Francisco Joaquim Catête, Luiz Affonso d'Escragnolle e Manoel Caetano de Gouvêa Junior.

A ata que evidencia tal informação está datada de 28 de maio de 1848, onde, após aquisição de cópia do documento original podemos ler:

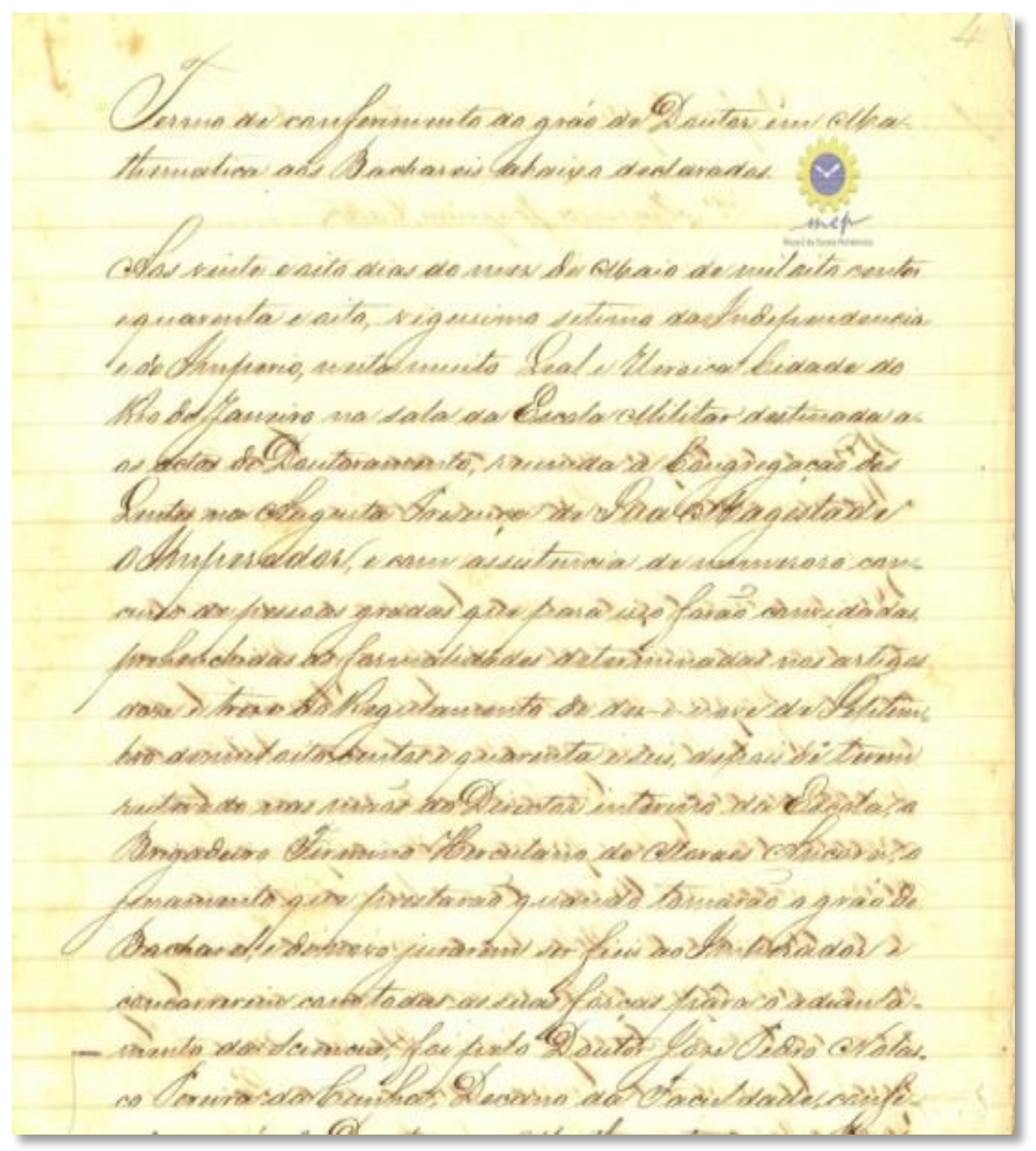

Figura 1: Termo de Conferimento de Grau de Doutor em Ciências Matemáticas 28/05/1848. Fonte: Acervo do Museu da Escola Politécnica da UFRJ 


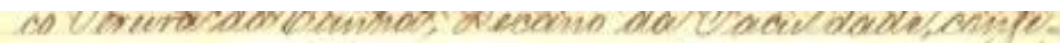

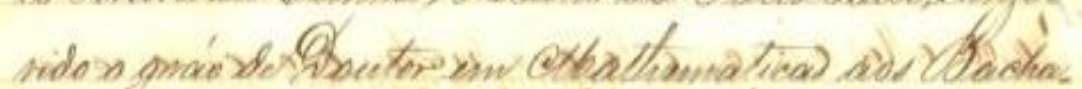

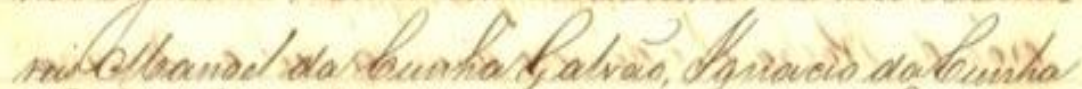

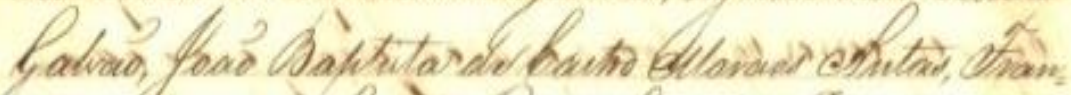

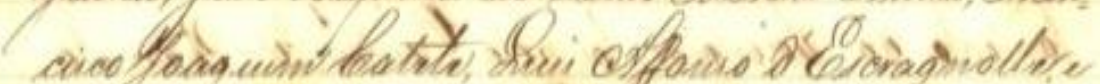

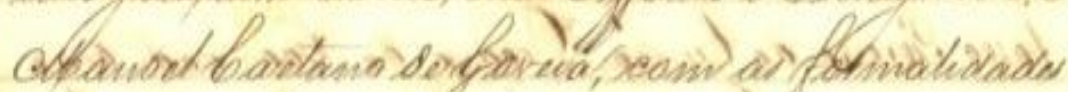

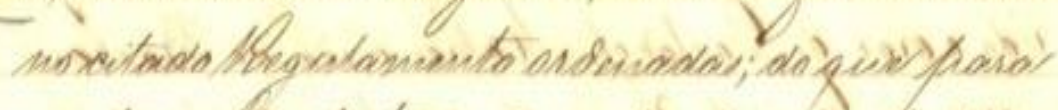

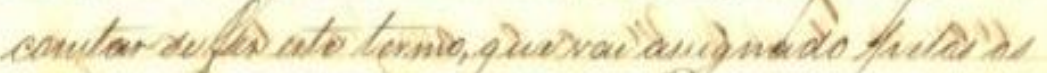

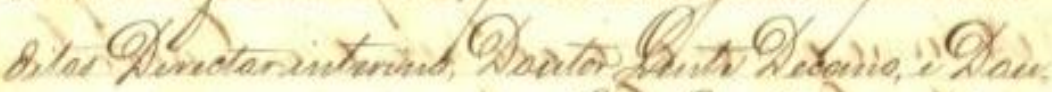

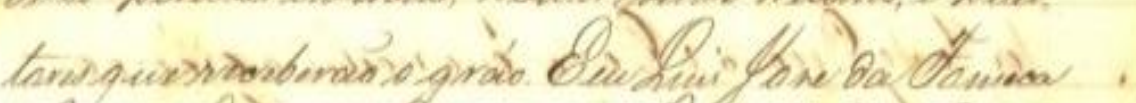

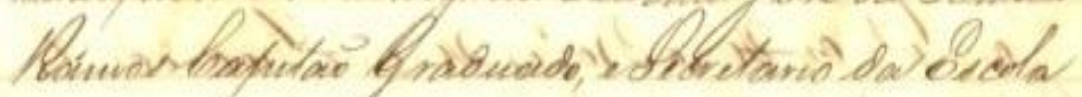
Whilitar so enderive:

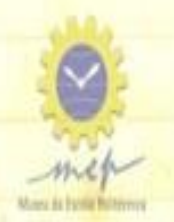

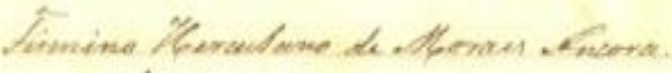

$$
\begin{aligned}
& \text { deir sinke: }
\end{aligned}
$$

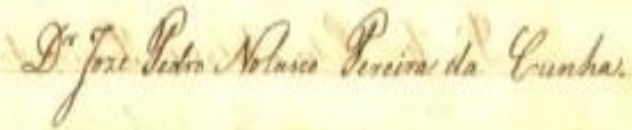

$$
\begin{aligned}
& \text { Q' } 16 \text { and ata tank gakn }
\end{aligned}
$$

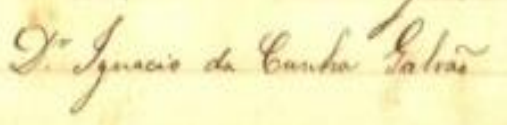

Figura 2: Continuação do termo de Conferimento de Grau de Doutor em Ciências Matemáticas 28/05/1848. Fonte: Acervo do Museu da Escola Politécnica da UFRJ

“Termo de Conferimento de gráo de Doutor em Ma- 
thematica aos Bachareis abaixo declarados.

Aos vinte e oito dias do mes de Maio de mil oitocentos e quarenta e oito, vigesimo setimo da Independencia e do Imperio, nesta muito Leal e Eroica cidade do Rio de Janeiro na sala da Escola Militar destinada aos actos de Doutoramento, reunida a Congregação dos Lentes na Augusta Presença de Sua Magestade o Imperador, e com assistencia de numeroso concurso de pessoas gradas que para is so farão convidadas prehenchidas as formalidades determinadas nos artigos doze e treze do Regulamento de dez-e-nove de Setembro de mil oitocentos e quarenta e seis, depois de terem reiteradi nas mãos do Diretor interino da Escola, o Brigadeiro Firmino Herculano de Moraes Ancora, o juramento que prestarão quando tomarão o gráo de Bacharel, e denovo jurarem ser fieis ao Imperador e concorrerem com todas as suas forças para o adiantamento da Sciencias, foi feito Doutor Jose Pedro Nolas co Pereira da Cunha, Decano da Faculdade, conferido o gráo de Doutor em Mathematicas aos Bachareis Manoel da Cunha Galvão, Ignacio da Cunha Galvão, João Baptista de Castro Moraes Antas, Francisco Joaquim Catete, Luis Affonso d'Escragnolle, e Manoel Caetano de Gouvea, com as formalidades no citado Regulamento ordenadas; do que para constar se fez este termo, que vai assignado pelas as ditas Diretor interino, Doutor Lente Decano, e Doutores que receberão o gráo. Eu Luis Jose da Fonseca Ramos Capitão Graduado, e Secretario da Escola Militar o escrevi.

Francisco Herculano de Moraes Ancora

Diretor Interino

Dr. Jose Pedro Nolasco Pereira da Cunha.

Dr Manuel da Cunha Galvão

RBHM, Vol. 17, n³3, p. 31-48, 2017 
Mônica C. Siqueira Martines \& Sérgio R. Nobre

Dr. Ignacio da Cunha Galvão

Dr. João Baptista de Castro Moraes Antas.

Dr. Luis Affonso d'Escragnolle.

Dr. Francisco Joaquim Catête."

As assinaturas de João Baptista de Castro Moraes Antas, Luis Affonso d'Escragnolle e Francisco Joaquim Catête encerram o documento na próxima folha, onde está presente a ata de 14 de Outubro de 1848. Nesta última apenas um Bacharel em Matemática recebe o grau de Doutor em Matemáticas sendo, portanto, o sétimo bacharel a receber o referido grau, como pode ser conferido nas palavras reproduzidas de cópia obtida do documento original. 


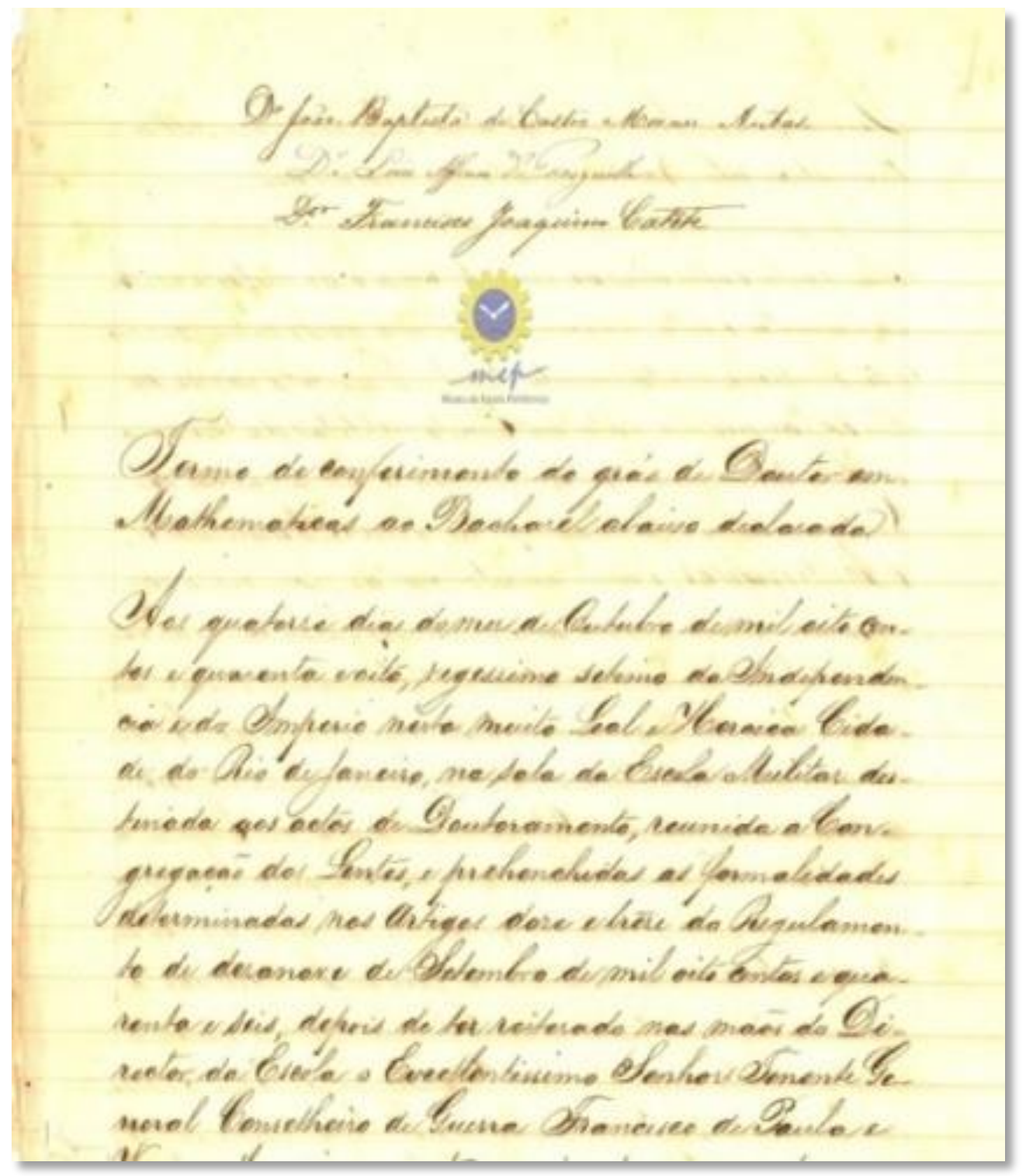

Figura 3: Termo de Conferimento de Grau de Doutor em Ciências Matemáticas 14/10/1848. Fonte: Acervo do Museu da Escola Politécnica da UFRJ 


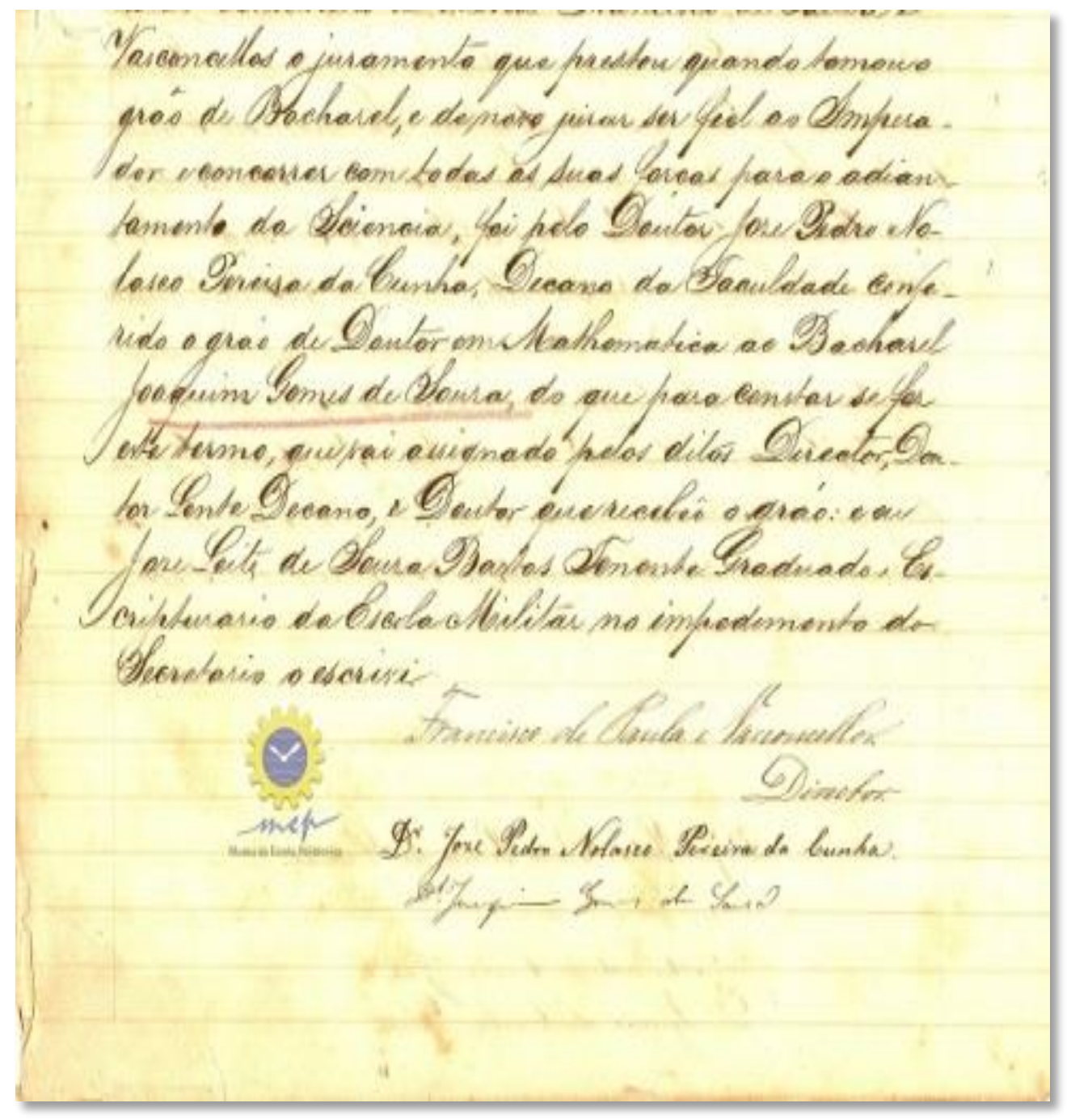

Figura 4: Continuação do Termo de Conferimento de Grau de Doutor em Ciências Matemáticas 14/10/1848. Fonte: Acervo do Museu da Escola Politécnica da UFRJ

"Termo de conferimento do gráo de Doutor em Mathematicas ao Bacharel abaixo declarado.

Aos quatorse dias do mes de Outubro de mil oito centos e quarenta e oito, vigessimo setimo da Independen- 
cia e do Imperio nesta muito Leal e Heroica Cidade do Rio de Janeiro, na sala da Escola Militar des tinada aos actos de Doutoramento, reunida a Congregação dos Lentes, e prehenchidas as formalidades determinadas nos artigos doze e trese do Regulamento de dezanove de Setembro de mil oito centos e quarenta e seis, depois de ter reiterado nas mãos do Director da Escola o Excellentis simo Senhor Tenente General Conselheiro de Guerra Francisco de Paula e Vasconcellos o juramento que prestou quando tomou o gráo de Bacharel, e de novo jurar ser fiel ao Imperador e concorrer com tos as as suas forças para o adiantamento da Sciencia, foi pelo Doutor Jose Pedro Nolasco Pereira da Cunha, Decano da Faculdade conferido o gráo de Doutor em Mathematica ao Bacharel Joaquim Gomes de Sousa, do que para constar se faz este termo, que vai assignado pelos ditos Director, Doutor Lente Decano, e Doutor que recebeô o gráo: e eu Jose Leite de Sousa Bastos Tenente Graduado e Es cripturario da Escola Militar no impedimento do Secretario o escrevi.

Francisco de Paula e Vasconcellos.

Diretor.

Dr. Jose Pedro Nolasco Pereira da Cunha.

Dr. Joaquim Gomes de Sousa."

Após analisarmos esses Termos, afirmamos, assim como Miller(2003) já havia feito em seu trabalho, que Sousinha não foi o primeiro a apresentar uma dissertação de Doutorado em Matemática no Brasil. Antes dele tivemos outros seis Doutores em Matemática.

No quadro a seguir, apresentamos as datas de entrega das dissertações do seis primeiros doutores, as mesmas podem ser encontradas nas dissertações de doutorado.

Quadro1: Primeiras Dis sertações de Doutorado apresentadas à Escola Militar

\begin{tabular}{c|c}
\hline Data de entrega & Autor \\
\hline $\mathbf{2 2 / 1 2 / 1 8 4 7}$ & Manuel da Cunha Galvão \\
\hline
\end{tabular}


O Primeiro Doutor em Ciências Matemáticas no Brasil: Manuel da Cunha Galvão

\begin{tabular}{c|c}
\hline $\mathbf{0 1 / 0 2 / 1 8 4 8}$ & João Baptista de Castro Moraes Antas \\
\hline $\mathbf{0 5} / \mathbf{0 2} / \mathbf{1 8 4 8}$ & Ignacio da Cunha Galvão \\
\hline $\mathbf{0 3 / 0 3 / 1 8 4 8}$ & Francisco Joaquim Catête \\
\hline $\mathbf{0 6 / 0 3 / 1 8 4 8}$ & Manoel Caetano de Gouvêa Junior \\
\hline $\mathbf{0 6 / 0 4 / 1 8 4 8}$ & Luiz Affonso d'Escragnolle \\
\hline
\end{tabular}

Fonte: Dis sertações de Doutorado

Também notamos que os seis primeiros bachareis que receberam o grau de Doutor assim o fizeram na presença do Imperador, diferentemente do sétimo a obter o referido grau. Verificamos que na primeira ata falta a assinatura de Manoel Caetano de Gouvêa Junior, mas não sabemos explicar por qual razão o recém-doutor não assinou o documento. Acreditamos que isso possa ser investigado com maior profundidade em um próximo trabalho.

\section{O primeiro Doutor em Ciências Matemáticas a entregar uma dissertação de Matemática no Brasil: Manuel da Cunha Galvão}

Manuel da Cunha Galvão, de acordo com Blake (1900, p.56), nasceu em Porto Alegre, Rio Grande do Sul, em 27 de setembro de 1822, e faleceu em 27 de março de 1872 (BLAKE, 1900, p.378).

Era filho de Manuel Raimundo Galvão e de Joaquina Teodora da Cunha, e irmão do tenente-coronel Ignacio da Cunha Galvão.

Casou em 30 de dezembro de 1854, no Rio de Janeiro, com Clemencia Augusta de Sales. Tiveram dois filhos: Julieta de Sales Galvão, nascida em 06 de outubro de 1855, no Rio de Janeiro, que se tornou a $2 .^{\text {a }}$ viscondessa da Graça, título português por seu casamento e não deixou filhos e Alberto de Sales Galvão, nascido em 22 de maio de 1861, no Rio de Janeiro.

Manuel da Cunha Galvão obteve o título de bacharel em letras pela Universidade de Paris, e nas palavras de Blake (1900, p.56) tornou-se "[...] doutor em mathematicas pela antiga escola militar do Rio de Janeiro, sendo o primeiro que aqui sustentou these para obter esse gráo, [...]”.

Serviu no corpo de engenheiros do exército até a patente de capitão. Depois de deixar o exército foi chefe de obras públicas e navegação e contribuiu para a criação da Secretaria de Estado dos negócios da agricultura, comércio e obras públicas, que depois daria origem tanto ao Ministério da Agricultura, quanto ao dos Transportes.

RBHM, Vol. 17, n³3, p. 31-48, 2017 
Foi presidente da província de Sergipe, e segundo Barata (?, p.2), foi nomeado por carta imperial de 31 de janeiro de 1859, empossado em 07 de março de 1859, deixando o cargo em 15 de agosto de 1860.

Ainda segundo Blake (1900), publicou cerca de 15 obras, entre elas a dissertação de doutorado; um projeto de organização de um ministério das obras públicas; alguns apontamentos sobre a distribuição das águas, dos serviços de es goto limpeza e calçamento da cidade, de banhos públicos e outros assuntos de higiene pública e particular; sobre a construção naval e o melhoramento dos portos do Brasil.

\section{A dissertação de Manuel da Cunha Galvão: um breve resumo}

Manuel da Cunha Galvão escreveu a dissertação intitulada "O Systema Planetário". A mesma foi entregue em 22 de dezembro de 1847 e, conforme o regulamento, o tema deveria ser escolhido pelo bacharel dentro de um dos assuntos que se ensinavam nos três últimos anos. A escolha de Manuel da Cunha Galvão se volta à disciplina que era ministrada no quarto ano primeira cadeira: Astronomia.

Sobre a escolha do tema o próprio autor afirma que:

"Cumprindo-me escrever uma dissertação, a primeira difficuldade que encontrei, e não pequena, foi a de escolher um ponto para assumpto do meu trabalho. No labyrintho em que me achei, não fui tão feliz como Theseo, que teve o fio de Ariadne para digil-o. No circulo em que tenho vivido, sempre foi a Mecanica Celeste de Laplace considerada como uma das obras que mais honra fazem ao espirito humano ". (GALVÃO, 1847, p.1)

Manuel comenta da dificuldade em não se ter um orientador para conduzir o caminho da pesquisa, desde a escolha do tema até o desenvolvimento da mesma. Mas vale lembrar que, naquela época, para obter o título de doutor, a dissertação não seria julgada por seu conteúdo, mas somente por não haver nada que desonras se as pessoas ou a coroa. $\mathrm{O}$ autor deixa claro que a escolha do tema foi dele, como estava previsto no Regulamento de 1846.

A dissertação de Manuel da Cunha Galvão foi desenvolvida em trinta e duas páginas e apresenta, ao final, uma página com figuras. Seu texto está dividido em alguns subtítulos, como podemos ver no quadro 2 .

Quadro 2: Divisões da Dissertação de Manuel da Cunha Galvão

\begin{tabular}{c|c}
\hline Subtítulo & Página \\
\hline Prefácio & 1 \\
\hline
\end{tabular}


O Primeiro Doutor em Ciências Matemáticas no Brasil: Manuel da Cunha Galvão

\begin{tabular}{c|c}
\hline Utilidade da Astronomia & 4 \\
\hline Systemas Diversos & 6 \\
\hline Leis de Kepler & 8 \\
\hline Da Attracção Universal & 10 \\
\hline Movimento dos Planetas & 13 \\
\hline Determinação das Distâncias dos Astros & 17 \\
\hline Determinação do Volume, da Massa e da Densidade dos & 18 \\
\hline Planetas & 19 \\
\hline Massa dos Planetas & 20 \\
\hline Densidade dos Planetas & 21 \\
\hline Dos tres Planetas Modernos & 22 \\
\hline Planeta Le Verrier & 24 \\
\hline Da Terra & 24 \\
\hline Sua Revolução & 25 \\
\hline sobre a Superfície da Terra & 25 \\
\hline Comparação da Massa da Atmosfera com a Massa da Terra & 25 \\
\hline Altura da Atmosfera Terrestre & 26 \\
\hline Dos Cometas & 27 \\
\hline Das Estrellas & 28 \\
\hline
\end{tabular}

Fonte: Dissertação de Manuel da Cunha Galvão

No Prefácio (o autor não intitula essas páginas iniciais como Prefácio, aqui a fizemos apenas para nos situarmos) cita a obra de Laplace, Mecânica Celeste, embora não revele o ano da publicação da mesma. Sabemos que a obra de Laplace influenciou a dissertação de Galvão, assim como de tantos outros, por ter sido este autor adotado ao longo da História da Escola Militar.

Entre as várias contribuições dadas em sua dissertação, chamamos atenção quando Galvão cita Le Verrier, o que mostra que Galvão se encontrava imerso nas mais recentes descobertas que vinham acontecendo no continente Europeu.

No subtítulo Planeta Le Verrier inicia dizendo que, na primeira sessão de $1^{\circ}$ de junho de 1846, da Academia de Ciências de Paris,

"Le Verrier apresentou seu trabalho, em que prova que não é possível representar as observações de Urano no systema da gravitação universal, na hypothese em que este planeta não esteja sujeito senão ás acções reunidas do sol e dos planetas conhecidos. Todas as anomalias 
observadas explicam-se pelo contrario nos seus menores detalhes, pela influencia de um novo planeta situado além de Urano, e que percorresse uma orbita determinada". (GALVÃO, 1847, p.22).

Aqui, observamos que Galvão estava atento às novidades na área de Astronomia, pois apresenta um fato recém ocorrido na França e que repercutiu no meio cientifíco da época, pois, conforme o autor mesmo nos revela, os ingleses tentaram reinvidicar a descoberta de Le Verrier para um jovem matemático de Cambridge chamado Adams. Os franceses alegaram que o inglês não havia publicado seus dados e por isso Le Verrier deveria levar as honras. Num relatório sobre a descoberta do planeta Le Verrier, Galvão nos conta a opinião do astrônomo inglês Challis,

"Nós podemos affirmar com certeza, como factos para os quaes ha provas materiaes, que o problema da determinação do lugar desconhecido do corpo perturbador, pelas perturbações, foi resolvido aqui na Inglaterra pela primeira vez; que nós fomos os primeiros a marcar a sua posição, e a deduzir das observações os elementos aproximados da sua orbita; que póde-se dizer que tudo isto é devido aos talentos e aos trabalhos de um de nós, que ao mesmo tempo honrou a universidade, e sustentou a honra scientifica do paiz". (GALVÃO, 1847, p.23).

Este fato esse corrobora com a afirmação de O'Connor e Robertson (2014), que aponta que Le Verrier descobriu o novo planeta através de cálculos e não por observações diretas, assim como o inglês Adams, que não publicou seus resultados de pesquisa. Segundo O’Connor e Robertson (2014), Le Verrier, ficou mais conhecido devido ao cálculo da posição de um planeta desconhecido. O que o levou a fazer tais cálculos foram as irregularidades apresentadas na órbita de Urano. Ainda de acordo com O'Connor e Robertson (2014), François Arago foi quem iniciou Le Verrier nos estudos das irregularidades da órbita de Urano, em 1845, e Le Verrier publicou seu primeiro artigo sobre o assunto em dezembro de 1845. Em junho de 1846 publicou o segundo artigo predizendo a posição do planeta hipotético. A análise das perturbações mostrou sua habilidade com os números, trabalhando com aproximações de sétima ordem e envolvendo 469 termos distintos. Em 18 de setembro de 1846, Le Verrier escreveu a Johann Galle do Observatório de Berlim, pedindo a ele para olhar para o planeta na posição prevista. Galle duvidou que os cálculos pudessem estar corretos e escreveu para Le Verrier que prontamente respondeu, dizendo confiar em seus cálculos. Galle então fez a observação e verificou que o planeta realmente existia e refez a observação no dia seguinte, confirmando a existência de um planeta de oitava magnitude. O'Connor e Robertson (2014) afirmam que 
um amigo de Le Verrier disse que ele descobriu uma estrela com a ponta de sua caneta, sem qualquer auxílio de instrumentos.

Galvão comenta que até o dia 26 de julho de 1847 ainda não haviam decidido sobre o nome do planeta: se seria Le Verrier, como queria Arago, ou Netuno, como queriam diversos astrônomos. Hoje sabemos o resultado.

Observamos que Galvão teve acesso a informações a respeito do que ocorria na Astronomia até pouco tempo antes da entrega de sua dissertação, mas não há qualquer referência sobre esses dados, de como ele os conseguiu. O autor continua relatando a descoberta de outro planeta, descoberto em 1 de julho de 1847 por Hencke de Driessen, o mesmo que descobriu o planeta Astréa, e este novo planeta também fica localizado entre Marte e Jupiter. Depois, apresenta alguns elementos a respeito desse planeta. O modo como ele sabia dessas notícias não é descrito em sua dissertação, mas podemos inferir que deveria manter contato com algumas pessoas na França, onde estudou.

A dissertação foi vista e aprovada nos termos do artigo $7^{\circ}$ do Regulamento pelo prof. Dr. José Gomes Jardim.

\section{Algumas considerações}

De posse das informações adquiridas pelas leituras dos decretos de reforma da Escola Militar desde sua criação em 1810, podemos entender que poucos alunos poderiam se candidatar ao grau de doutor em Ciências Matemáticas em meados do século XIX no Brasil, pois, além de passar por uma seleção antes de frequentarem a referida escola, ou seja, passar pelos exames preparatórios, deveriam cursar os sete anos da Escola Militar e obter aprovações plenas em todas as disciplinas, o que não era fácil devido ao nível de dificuldade das mesmas.

O primeiro bacharel em Matemática a obter o título de Doutor em Ciências Matemáticas, Manuel da Cunha Galvão, entregou sua dissertação em 22 de dezembro de 1847, recebeu o grau de Doutor na presença do Imperador do Brasil e, escolheu Astronomia como tema para apresentar. Inferimos que da forma como tratou o assunto, mostrou seu grau de conhecimento sobre o mesmo, inclusive mostrando atualidades sobre o assunto. Comenta sobre o Planeta Le Verrier, hoje chamado Netuno, deixando claro que este cientista descobriu o planeta sem observação direta, somente usando cálculos. A dissertação foi vista e aprovada nos termos do Regulamento pelo Dr. José Gomes Jardim, que julgou não sobre o merecimento científico, mas sobre se não constava nada na dissertação que desilustrasse qualquer pessoa da corte.

O primeiro doutor em Ciências Matemáticas no Brasil desempenhou atividades politicas no País, sendo de grande importância como figura pública. 
A pesquisa continua e agora pretendemos verificar o dossiê desse cientista, acrescentando assimnovos elementos a História da Matemática do Brasil.

\section{Bibliografia}

BLAKE, Augusto Victorino Alves Sacramento. Diccionario bibliographico brazileiro. Rio de Janeiro: Typographia Nacional, 1893. vol. 2.

BRASIL. Carta de Lei de 4 de Dezembro de 1810. Crea uma Academia Real Militar na Côrte e Cidade do Rio de Janeiro. Lex: Coleção de Leis do Império do Brasil - 1810 ,

Página 232 Vol. $1 . \quad$ Disponível em: <http://www2.camara.gov.br/legin/fed/carlei/anterioresa1824/cartadelei-40009-4dezembro-1810-571420-norma-pe.html>. Acesso em: 12 de jul. 2012.

BRASIL. Decreto de 9 de Março de 1832. Reforma a Academia Militar da Côrte encorporando nella a dos Guardas Marinhas; e dá-lhe novos estatutos. Lex: Colecção das Leis do Brazil, 1831-1840, Atos do Poder Executivo - 1832. Leis do Império. Disponível em http://www2.camara.gov.br/atividade-legis lativa/legis lacao/publicacoes/doimperio. Consulta realizada em 26 de jul. 2012.

BRASIL. Decreto de 22 de Outubro de 1833. Separa a Academia de Marinha, e a companhia dos Guardas Marinhas, da Academia Militar da Côrte, e dá a esta novos estatutos. Lex: Colecção das Leis do Brazil, 1831-1840, Atos do Poder Executivo - 1833. Leis do Império. Disponível em http://www2.camara.gov.br/atividadelegislativa/legislacao/publicacoes/doimperio. Consulta realizada em 26 de jul. de 2012.

BRASIL. Decreto de 23 de Fevereiro de 1835. Manda que fique de nenhum effeito os Estatutos para a Academia Militar de 22 de Outubro de 1833, e que se observem os de 9 de Março de 1832, que baixarão com o Decreto desta data, com as seguintes alterações. Lex: Colecção das Leis do Brazil, 1831-1840, Atos do Poder Executivo - 1835. Leis do Império. Disponível em http://www2.camara.gov.br/atividadelegis lativa/legis lacao/publicacoes/doimperio. Consulta realizada em 26 de jul. de 2012.

BRASIL. Decreto de 14 de Janeiro de 1839. Lex: Colecção das Leis do Brazil, 18311840, Atos do Poder Executivo - 1839. Leis do Império. Disponível em http://www2.camara.gov.br/atividade-legis lativa/legis lacao/\\publicacoes/doimperio.

Consulta realizada em 26 de jul. 2012.

BRASIL. Decreto n 140 - 09 de Março de 1842. Approva os Estatutos da Escola Militar, em virtude do Artigo $15 \S 2^{\circ}$ da Lei de 15 de Novembro de 1831. Lex: Colecção das Leis do Brazil, 1831-1840, Atos do Poder Executivo - 1831. Leis do Império. Disponível em http://www2.camara.gov.br/atividade-legis lativa/legislacao/publicacoes/doimperio.

Consulta realizada em 26 de jul. 2012. 
BRASIL. Decreto n⿳0404 - de 1 de Março de 1845. Manda executar provisoriamente os estatutos da Escola Militar, em virtude do Art.15 $\S 2^{\circ}$ da Lei de 15 de Novembro de 1831. Lex: Colecção das Leis do Brazil, 1841-1850, Atos do Poder Executivo - 1845. Leis do Império. Disponível em http://www2.camara.gov.br/atividadelegislativa/legislacao/publicacoes/doimperio. Consulta realizada em 31 de jan. 2013.

BRASIL. Decreto no 476 de 29 de setembro de 1846. Appovando o Regulamento para execução do Artigo 17 dos Estatutos da Escola Militar. Lex: Colecção das Leis do Brazil, 1831-1840, Atos do Poder Executivo - 1846. Leis do Império. Disponível em http://www2.camara.gov.br/atividade-

legislativa/legislacao/publicacoes/doimperio.Consulta realizada em 26 de jul. de 2012.

BRASIL. Carta Régia de 29 de Dezembro de 1815. Crêa um curso completo de Cirurgia na Cidade da Bahia, e manda executar nella provisoriamente o plano dado para o curso desta Côrte. Coleção de Leis do Império do Brasil - 1815, Página 64 Vol. 1 (Publicação Original). Disponível em http://www2.camara.leg.br/legin/fed/carreg sn/anterioresa1824/cartaregia-39555-29dezembro-1815-569931-publicacaoorig inal-93096-pe.html. Acesso em 25 de nov. de 2013. BRASIL. Carta Régia de 29 de Dezembro de 1815. Crêa um curso completo de Cirurgia na Cidade da Bahia, e manda executar nella provisoriamente o plano dado para o curso desta Côrte\}. Coleção de Leis do Império do Brasil - 1815, Página 64 Vol. 1 (Publicação Original). Disponível em: http://www2.camara.leg.br/legin/fed/carreg\_sn/anterioresa1824/cartaregia-39555-29-

dezembro-1815-569931-publicacaoorig inal-93096-pe.ht ml. Acesso em 25 de nov. de 2013. BRASIL. Projeto de regulamento ou estatuto para o Curso Juridico pelo Decreto de 9 de Janeiro de 1825, organizado pelo Conselheiro de Estado Visconde da cachoeira, e mandado observar provisoriamente nos Cursos Juridicos de S. Paulo e Olinda pelo art $10^{\circ}$ desta lei. Coleção de Leis do Império do Brasil - 1827, Página 5 Vol. 1 pt. I (Publicação Original). Disponível em http://www2.camara.leg.br/legin/fed/leil_sn/1824-1899/lei38401-11-agosto-1827-566698-publicacaooriginal-90225-pl.html. Acesso em 25 de nov. de 2013.

GALVÃO, Manuel da Cunha. O Systema Planetario. Rio de Janeiro, 1847. Tese de Doutorado - Faculdade de Mathematicas da Escola Militar do Rio de Janeiro.

MENDES, Iran A. A investigação histórica como agente de cognição matemática na sala de aula. In: A história como agente de cognição na Educação Matemática. Porto Alegre: Sulina, 2006.

MILLER, Célia Peitl. O Doutorado em matemática no Brasil: um estudo histórico documentado (1842-1937). Rio Claro: 2003. Dissertação de mestrado - Universidade Estadual Paulista, Instituto de Geociências e Ciências Exatas. 
O'CONNOR, J.J; ROBERTSON, E.F. (2014). Urbain Jean Joseph Le Verrier. Disponível em <http://www-history.mcs.st-and.ac.uk/Biographies/Le_Verrierl.html>. Consulta realizada em 29 de jan. de 2014.

Mônica de Cássia Siqueira Martines
Departamento de Matemática - UFTM - Uberaba -
Brasil
E-mail: monica.siqueiramartines @uftm.edu.br
Sergio Roberto Nobre
$\begin{aligned} & \text { Departamento de Matemática - UNESP - Rio Claro - } \\ & \text { SP - Brasil }\end{aligned}$
E-mail:sernobre @ rc.unesp.br

